\section{Journal of Medical Microbiology and Infectious Diseases}

JIOMMMIID)

ISSN: 2345-5349

eISSN: $2345-5330$

\title{
Emerging Epidemics of Cutaneous Leishmaniasis in Iran: Operational Aspects, Management and Implemented Control Approaches
}

\author{
Mohammad Reza Aflatoonian ${ }^{1}$, Iraj Sharifi ${ }^{2 *}$, Zahra Babaei ${ }^{2}$, Fatemeh Sharifi $^{3}$, Alireza Keyhani ${ }^{2}$, Ehsan \\ Salarkia $^{2}$, Ahmad Khosravi ${ }^{2}$, Ali Khamesipour ${ }^{4}$, Mehdi Mohebali ${ }^{5}$, Abolhassan Nadim ${ }^{5}$, Mehdi Bamorovat ${ }^{2}$ \\ ${ }^{1}$ Research Center of Tropical and Infectious Diseases, Kerman University of Medical Sciences, Kerman, Iran; \\ ${ }^{2}$ Leishmaniasis Research Center, Kerman University of Medical Sciences, Kerman, Iran; ${ }^{3}$ Pharmaceutics Research \\ Center, Institute of Neuropharmacology, Kerman University of Medical Sciences, Kerman, Iran; ${ }^{4}$ Center for Research \\ and Training in Skin Diseases \& Leprosy, Tehran University of Medical Sciences, Tehran, Iran; ${ }^{5}$ Department of Medical \\ Parasitology and Mycology, School of Public Health, Tehran University of Medical Sciences, Tehran, Iran
}

\begin{tabular}{|c|c|}
\hline R T I C L E I N F O & A B S T R A C T \\
\hline Review Article & $\begin{array}{l}\text { Cutaneous leishmaniasis (CL) in Iran could be considered as an emerging disease that } \\
\text { is rapidly increasing and expanding its traditional geographical range to new foci. }\end{array}$ \\
\hline $\begin{array}{l}\text { Keywords: Emerging epidemics, } \\
\text { Cutaneous leishmaniasis, Risk factors, } \\
\text { Management and control, Iran }\end{array}$ & $\begin{array}{l}\text { Sixteen registered emerging epidemics have occurred since } 1998 \text { in different provinces. } \\
\text { Various risk factors, including agricultural development, earthquake, movement to } \\
\text { endemic areas, construction of buildings near colonies of rodents, sleeping outside, } \\
\text { cross-border movements, and poor sanitation, play crucial roles in the expansion of the }\end{array}$ \\
\hline eceived Jul 022019 & disease. The mentioned risk factors can lead to the gradual or sudden emergence of new \\
\hline ed form: Jan. 08,2020 & also erupt into epidemics. This paper \\
\hline 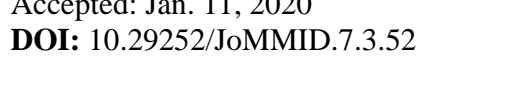 & $\begin{array}{l}\text { reviews the emerging epidemics published between } 1998 \text { and } 2019 \text { in Iran with } \\
\text { particular emphasis on the operational aspects of control and related risk factors caused }\end{array}$ \\
\hline & $\begin{array}{l}\text { by anthroponotic CL (ACL) and zoonotic CL (ZCL). The competent surveillance } \\
\text { system should be extended to all high-risk areas to facilitate controlling the emerging } \\
\text { epidemics of ACL and ZCL in the affected areas. }\end{array}$ \\
\hline
\end{tabular}

Fax: +983413239843

\section{INTRODUCTION}

Leishmaniasis remains a significant health problem with growing serious health impacts, more frequently in the Eastern Mediterranean Region (EMR), Indian Subcontinent, Latin America, and Africa [1]. Leishmaniasis is neglected mainly in tropical countries and constitutes the ninth-largest disease burden in terms of global morbidity and mortality among infectious diseases [2].

The disease occurs in 98 countries and three territories on four continents [3], where approximately 12 million people are affected, over one billion people are currently at risk and 1-2 million new cases occur annually [4]. Cutaneous leishmaniasis (CL) is the most common form of the disease, representing $75 \%$ of the total cases in which more than $90 \%$ of the cases are from Afghanistan, Iran, Iraq, Syria, Algeria, Saudi Arabia, Peru and Brazil [5]. CL is mostly unreported and concentrated in remote rural areas or urban slums [2].

Over the past decades, global data indicated emergence of new CL foci in different countries, i.e., Bolivia [6], Pakistan [7], Afghanistan [8], Morocco [9], Israel [10], Brazil [11], Libya [12], Sri Lanka [13], Europe [14] and Iran [15]. Various risk factors including environmental modifications due to urbanization and natural disasters, lack of competent vector and reservoir control strategies, population displacements, drug resistance, poor sanitation, and human behaviors play essential roles in expansion of the disease [1,5,16-19]. The mentioned risk factors can converge to gradual or sudden emergence of epidemics and longlasting endemic foci can also erupt into epidemics [11].

National reports by the Ministry of Health and Medical Education (MOHME) in Iran have shown an average incidence rate of 20 and 40 cases per 100,000 people $[15,20]$. In Iran, this disease occurs in 17 of 31 provinces. In recent years, official reports indicate an average of 15,000-20,000 cases per year. Although CL is among the notifiable diseases, the real incidence is underestimated as many people with CL in the endemic areas, particularly in remote ones, do not usually refer to physicians. This portion varies with the area, indicating an underreporting of the actual burden of the disease.

This review focuses on the published works between 1998 and 2019 on anthroponotic cutaneous leishmaniasis (ACL) and zoonotic cutaneous leishmaniasis (ZCL), the two 
primary manifestations of the disease in Iran, and the adopted control measures.

Here, we discuss various aspects of the emerging epidemics of CL in Iran. We also reviewed the practical aspects of control approaches, and implementation of preventive measures including environmental management, chemical control strategies, vector, and reservoir incrimination and control approaches, personal protective measures, detection (passive and/or active) and identification of cases, treatment and referral of CL patients to higher provincial levels. Our literature review indicated no previous report on the topic. Therefore, to our knowledge, this work was the first comprehensive review of the CL emerging epidemics which explores the operational aspects of CL in Iran.

Emerging epidemics. CL falls into the category of emerging diseases, which includes those that either have recently appeared in populations, or are of a rapid increase in incidence or expanding their geographic range to new foci [21]. CL appears to be an emerging disease in most parts of Iran, north-east Afghanistan [8], and north-west Pakistan [7]. In Iran, epidemiological data indicate a considerable rise in $\mathrm{CL}$ in many provinces defined as emerging foci (Table 1]. The majority of the recent epidemics have stricken central provinces of Qom [22,23] and Isfahan [24] down to the south [23], southeast [25-31] and central [24] of the country (Fig. 1]. Outbreaks and epidemics are characteristics of both ACL and ZCL, which are caused by Leishmania tropica and Leishmania major, respectively.

In Iran, L. tropica causes ACL, which is transmitted by Phlebotomus sergenti, a sandfly that lives equally well in the vicinity of human habitation or far from people, and the human (Homo sapiens) is the reservoir host [11]. This species tends to live in towns and villages inside the affected human populations, mainly in the emerging epidemic foci of the two neighboring provinces of Iran (Fig. 1]; Kerman [3234] and Yazd [35]. The causative agent of ZCL, L. major, is transmitted by the sandfly, Phlebotomus papatasi. This species has an extensive distribution range in semi-arid landscapes, and it is frequently synanthropic (living in close association with the human) but also lives far from human habitation. The distribution range of this species is broader than that of Ph. sergenti, which is limited by the presence of suitable reservoir hosts [36-38]. It feeds on a wide variety of hosts, including mammals particularly gerbils and humans [39-43].

Emerging outbreaks of both ACL and ZCL are often associated with migration and the introduction of susceptible individuals into endemic areas where anthroponotic or enzootic transmission cycle is established. Seasonal labor movements may also spread the disease, with the return of migrants to endemic areas, as appears to have occurred in several foci in Kerman [25,29,31,35,44], Yazd [35] and Sistan and Baluchistan [45], Fars [46] and Isfahan [24] provinces.

Cross-border movement is also a significant risk factor $[1,5,45]$. Many new-comers from endemic areas of Pakistan and Afghanistan cross-border and arrive in different provinces of the country. Such infected migrant carriers are believed to be the primary source of outbreaks in some parts of Iran. Other contributory factors favoring transmission of CL included primitive housing conditions and low standards of hygiene, which increase the risk of transmission in urban and peri-urban areas. For instance, construction of buildings near rodent colonies [22,24], organic remnants, piles of bricks, and stones constitute potential breeding and resting sites for sand flies [24]. Generally, CL is a disease of poverty that is more prevalent among low-income groups and those with limited access to health care facilities [11].

Control strategies. In most instances, no single effective measure is available to reduce transmission, and commonly a combination of various approaches is more effective. Control measures can be implemented in the case of epidemics, but they need to be based on previous experience which is adapted to local conditions. In all instances, the following measures should be undertaken immediately [36].

Assigning a health clinic. The first step to control an emerging epidemic of CL is to establish a specific health clinic. This clinic can be used as a headquarter for various activities involved in the course of the control program. In the southeastern Iranian district of Bam and the surrounding cities, the emerging epidemics of CL occurred in several foci, after the massive earthquake in 2003 [18,25-27,29-31,44,47]. Most of the control activities including personnel training, face-to-face health education, diagnosis and identification of CL cases, treatment of patients, active and passive casefinding, implementation of vector control measures, modification of the physical environment, and referral of non-healing cases to specialists or assigned clinics, were initiated.

Detecting and identifying cases. The initial lesion starts as an erythematous papule (Fig. 2A) and then develops to a painless nodule (Fig. 2B), which may produce a nodule and pruritus. The papule or nodule may heal without developing into an ulcer or other clinical forms. The nodules usually ulcerate in a volcanic or satellite form; elongated lesions tend to align along skin creases or evolve to one of the several clinical forms of the disease (Fig. 2A-I). Various clinical presentations might develope due to the generation of strain or species specificity of the causative agent and also specific types of immune responses to Leishmania infection $[26,48,49]$. The lesions may heal spontaneously and leave small scars or produce a large scar (Fig. 2J).

For parasitological diagnosis, skin scraping is obtained from the edge of the active lesion using a small scalpel and blade. A smear is prepared from the materials obtained, fixed, and stained by Giemsa or an equivalent stain and microscopically examined for detecting amastigotes [50]. Simultaneously, another specimen should be obtained for culture in simple biphasic media such as Novy-MacNealNicolle (NNN) medium and then subculture in RPMI1640 for further characterization of the causative agent to strain or species level by molecular (PCR) or biochemical (isoenzyme electrophoresis) techniques and/or in some instances animal inoculation [11,50,51]. The availability of powerful new tools expands the power of laboratory-based surveillance and increases the feasibility of field applications. Identification of the causative agent is essential for treatment modality and 
strategy planning [36,52].

Treating the cases. The standard therapy for all clinical forms of leishmaniasis is pentavalent antimonial drugs, including meglumine antimoniate (Glucantime) and sodium stibogluconate (Pentostam), although the latter drug has currently no further use in the treatment of leishmaniasis [52]. Most of the clinical features are unresponsive to therapy and serve as the primary source for the transmission of the Leishmania agent [19,48,53-55].

In Iran, meglumine antimoniate is the drug of choice, which is given by systemic or intralesional injections, as recommended by WHO [62] and by the guidelines of the MOHME [15]. Glucantime is given to the patients free of charge by the governmental health clinics throughout the country. This drug is frequently used in combination with the second-line compounds or along with cryotherapy [15]. Unfortunately, this medication is of limited use due to prolonged treatment schedule, toxicity, parenteral administration and emergence of resistance $[63,64]$. For the treatment of non-healing forms of CL, such as lupoid leishmaniasis, a frequent sequel of ACL, a combination of Glucantime and allopurinol has been used with acceptable efficacy [65].

Personal protection measures. Individual protective measures in endemic and emerging epidemic foci include the application of repellents, such as diethyltoluamide (DEET), to skin or clothing to reduce man-vector contact. Bednets, screens, and curtains impregnated with insecticides such as permethrin or deltamethrin may provide proper protection [66-68]. Dressing of the lesions reduces the contacts between humans and the biological vector [15]. Data exhibited that implementation of impregnated bed nets and insecticide residual spraying (IRS) and long-lasting insecticide-treated nets (LLITNs) were highly effective in the control of the principal vectors against both ACL and ZCL in endemic areas of the country; although, they are not well accepted behaviorally $[66,67,69,70]$.

Environmental management. Modification of the physical environment may have a dramatic effect on the relative abundance of vectors and levels of transmission. Actual or potential sand fly breeding sites, such as rubble and garbage piles, can be eliminated through community involvement in urban and peri-urban areas to help control the vector population. About 10 million tons of debris and raw bricks were removed after the 2003 Bam earthquake [71]. Climate change has not been well studied in Iran, although it plays an important role and might have substantial effects on the ecology and distribution of vectors and reservoir hosts. Global warming, rainfall, and humidity are expected to affect the epidemiology of CL by several mechanisms, which in turn could lead to massive movement and migration of people to CL endemic areas, where the transmission cycle is active $[5,13,16]$.

Table 1. Emerging epidemics of cutaneous leishmaniasis in Iran, 1998 to present

\begin{tabular}{|c|c|c|c|c|c|}
\hline $\begin{array}{l}\text { Region or } \\
\text { district/province }\end{array}$ & $\begin{array}{l}\text { Occurrence } \\
\text { year }\end{array}$ & Main risk factor & Identification method & $\begin{array}{l}\text { Cutaneous } \\
\text { form }\end{array}$ & Reference \\
\hline Orzoeihe/Kerman & 1998 & Agricultural development & $\begin{array}{l}\text { ELISA, IFAT\& } \\
\text { mouse inoculation }\end{array}$ & ZCL & {$[27]$} \\
\hline Ardestan/Isfahan & 1998-1999 & Construction of buildings (rapid urbanization) & Isoenzyme & ZCL & {$[24]$} \\
\hline Ghanavat/Qom & $1998-2001$ & $\begin{array}{l}\text { Construction of buildings near colonies of rodents \& } \\
\text { movement to endemic areas }\end{array}$ & RAPD-PCR & $\mathrm{ZCL}$ & {$[22]$} \\
\hline Yazd/Yazd & $1999-2000$ & Human movement \& high density of vector & RAPD-PCR & ACL & [35] \\
\hline Ardakan/Yazd & 2001 & $\begin{array}{l}\text { Construction of buildings near colonies of rodents, } \\
\text { sleeping outside \& agricultural development }\end{array}$ & RAPD-PCR & $\mathrm{ZCL}$ & {$[56]$} \\
\hline $\begin{array}{l}\text { Sabzevar/ Khorasan } \\
\text { Razavi }\end{array}$ & 2001-2002 & $\begin{array}{l}\text { Construction of buildings near colonies of rodents, } \\
\text { poor sanitation\& sleeping outside }\end{array}$ & RAPD-PCR & ZCL & [57] \\
\hline Bam/Kerman & 2008 & Earthquake & Conventional PCR & ACL & {$[58]$} \\
\hline Zarindasht/Fars & 2003 & Earthquake & Conventional PCR & $\mathrm{ZCL}$ & [59] \\
\hline Shiraz/Fars & 2003 & Construction of buildings & Nested-PCR & $\mathrm{ZCL}$ & {$[46]$} \\
\hline $\begin{array}{l}\text { Mirjaveh/ } \\
\text { Sistan\&bluchestan }\end{array}$ & $2005-2006$ & Cross-border movements & $\begin{array}{l}\text { Conventional PCR \& } \\
\text { mouse inoculation }\end{array}$ & $\mathrm{ZCL}$ & [45] \\
\hline $\begin{array}{l}\text { Ghomrood\&Ghavavat } \\
\text { /Qom }\end{array}$ & 2006-2011 & Immigrants & ITS1-PCR & $\mathrm{ZCL}$ & [23] \\
\hline $\begin{array}{l}\text { Dehbakri } \\
\text { Bam/Kerman }\end{array}$ & 2008 & Movement to ACL endemic areas & Conventional PCR & ACL & [31] \\
\hline $\begin{array}{l}\text { Mohammadabad } \\
\text { Jiroft/Kerman }\end{array}$ & 2008 & Movement to ACL endemic areas & Nested-PCR & ACL & {$[44]$} \\
\hline $\begin{array}{l}\text { Bahraman/Rafsanjan, } \\
\text { Kerman }\end{array}$ & 2006-2010 & Colonies of rodents, human habitations & Conventional PCR & $\mathrm{ZCL}$ & {$[60,61]$} \\
\hline $\begin{array}{l}\text { Nezamabad } \\
\text { Bam/Kerman }\end{array}$ & 2010 & Movement to ACL endemic areas & Conventional PCR & ACL & {$[25]$} \\
\hline Abdanan/Ilam & 2015-2016 & Multiple & RFLP-PCR & $\mathrm{ZCL}$ & [17] \\
\hline $\begin{array}{l}\text { Narmashir } \\
\text { county/Kerman }\end{array}$ & 2016 & Population displacement & HRM-PCR & ACL & [18] \\
\hline
\end{tabular}




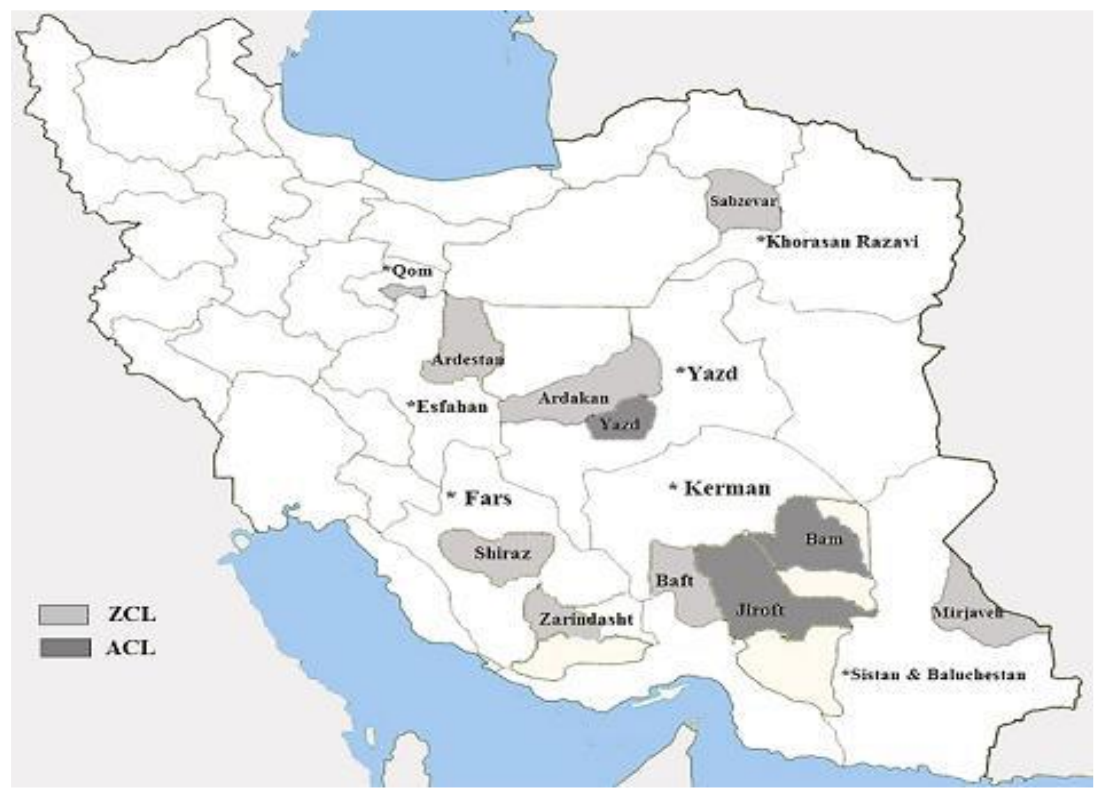

Fig. 1. Geographical distribution of emerging epidemics of anthroponotic cutaneous leishmaniasis (ACL) and zoonotic cutaneous leishmaniasis (ZCL) in Iran, 1998-2019
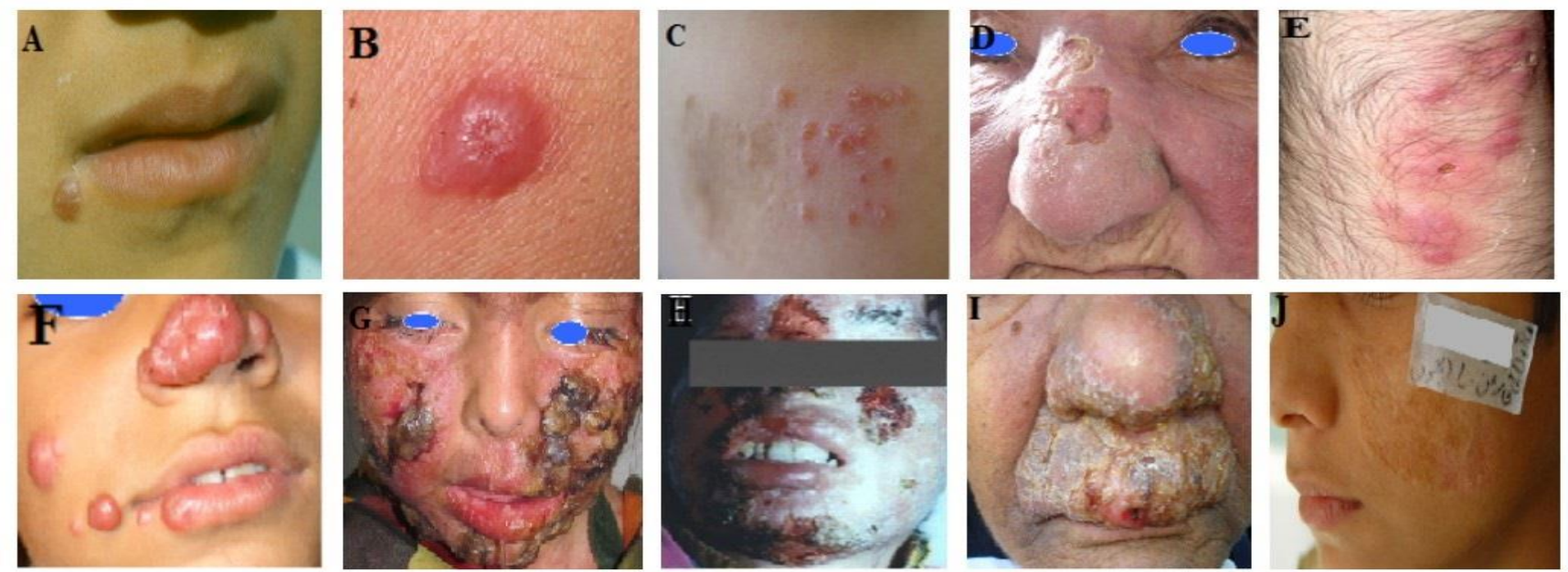

Fig. 2. Representative of skin lesions observed in cutaneous leishmaniasis patients in epidemic foci of Iran [53]: (A) An erythematous papule, (B) a nodule, (C) lupoid leishmaniasis, (D) an erysipeloid, (E) sporotrichoid, (F) diffuse cutaneous lesions, (G) disseminated cutaneous leishmaniasis, $(\mathrm{H})$ multiple cutaneous ulcers, (I) ulcerated lesions with lymph edema, $(\mathrm{J})$ a vast scar.

A significant risk factor in Orzoeihe district in the western province of Kerman, southeast of Iran, was established with the new water wells and electric pumps, which created new irrigation schemes and cultivation of new crops. This new agricultural project provoked a sharp change in the reproduction patterns of the main reservoir, i.e., the gerbils $[26,27]$. A large area was cultivated with cucumbers, melons, and various other grain crops, which provided an extraordinarily suitable source of food for gerbils and breeding of vector for ZCL. Consequently, there was a sudden increase in the population of rodents and vectors, followed by an epidemic of ZCL in rural residential areas [26-28].

Other contributing factors can also trigger and increase the rate of the CL epidemics and facilitate the broader and more rapid spread of infection. Following the earthquake in Bam, various occupational positions became available during the reconstruction of buildings. Economic conditions encouraged mass movement $[25,29,31,44]$ from various provinces particularly Fars [46] and Qom [22,23] to the affected areas. Numerous susceptible labor forces, mostly from non-endemic areas within the province and from other provinces of the country, traveled to disastrous areas, where active foci of $\mathrm{CL}$ were present. Migration is a significant risk factor for ACL $[13,72]$.

Incriminating vectors. A wide range of vectors continues to be incriminated in foci in different parts of the country $[32,37,60]$. However, the role of some vectors in the transmission of CL has not well been established. Among different species of phlebotomine sand flies, only $P h$. 
sergenti and $P h$. papatasi are incriminated as the principal biological vectors of ACL and ZCL, respectively [24,32,3941,43,73,74].

Incriminating reservoir hosts. The reservoir hosts vary among foci and must be carefully determined before the adoption of control measures. Despite Leishmania spp. isolation from various species of gerbils, the role of these rodents in the maintenance of $L$. major requires more studies and elucidation. Rhombomys opimus, the great gerbil, is the primary reservoir host of $L$. major in the arid regions of central Iran [75-77]. However, Tatera indica, Meriones libycus and Meriones hurrianae are other important reservoir rodents in some foci $[38,42,78]$.

While ZCL is confined to small rodents, the primary reservoir host in most provinces of Iran, and comprise approximately $80 \%$ of the total cases of human CL caused to L. major, ACL encompasses only $20 \%$ of the overall cases [15]. In Iran, ACL is induced by L. tropica which is largely limited to humans, but incidental cases of dogs have also been reported in some ACL foci. This fact represents that dogs may also be implicated in the life cycle of the parasite and play a secondary role in transmission of the L. tropica infection [79-83].

Control of ACL. Control of ACL is mainly limited to early diagnosis and prompt treatment of patients through an effective surveillance system which requires a dedicated active and passive case-detection [30,36]. At present, no vaccine is available $[68,84,85]$, and the use of first-line drugs, i.e., the pentavalent antimonials, is limited due to toxicity, low efficacy, cost, and the emergence of drug resistance $[52,63,64]$. In the Old World, leishmaniasis recidivans (lupoid leishmaniasis), is usually caused by $L$. tropica and become destructive and disfiguring over the years $[47,49,65]$. In foci of ACL, particularly in Bam lupoid lesions last for many years and patients might carry parasites throughout the long periods of several sessions of transmission cycles $[47,62]$. During Bam epidemics, insecticide spraying of houses, outdoor yards, and high-risk areas was repeatedly practiced to control $\mathrm{Ph}$. sergenti; however, these methods were not adequately evaluated $[29,31,86]$. Application of large scale impregnated screens and curtains in high-risk areas of the city of Bam [68] have also shown significant short-term efficacies. The results also suggested that shrinkage in the human reservoir pool in response to the intervention might play a significant role in prolonging the preventive effect beyond the insecticidal life of impregnated materials in foci of ACL. Special attention should be paid to those with underlying diseases including diabetics, young children, opium addicted individuals, HIV coinfection and those with chronic diseases [19,87-89] who might be at higher risk of contracting severe infection, particularly during the transmission season.

Control of ZCL. Control of ZCL is very different from ACL since it occurs in an acute form with shorter duration time and often needs no treatment. In emerging epidemics, control efforts should be directed toward gerbils as the primary reservoir host and also $P h$. papatasi as the primary biological vector. In the foci where R. opimus is the primary host, the inexpensive and remarkably effective approach
$[19,76,77]$ was using zinc phosphide $[2.5 \%)$ as a rodenticide. Rhombomys is readily identifiable by its burrow system and distinctive morphology [61,75]. This control program has significantly reduced the incidence rate of $\mathrm{ZCL}$ when compared to the control group at the end of the first and second year of operation [77].

Malarial spraying impact. Malaria control programs, based on outdoor and indoor residual insecticide spraying, have introduced a side benefit for leishmaniasis control and decreased its incidence in endemic areas [90]. In many areas, the resurgence of leishmaniasis is believed to be due to the cessation of these campaigns.

\section{CONCLISION}

In Iran, CL appears as an emerging disease with a significant burden and serious public health impact. This disease is rapidly increasing and expanding its geographic range to new foci in most provinces of the country. Various risk factors played essential roles in increasing the CL cases, which consist of environmental modifications due to urbanization and disasters, population movements, lack of vector and reservoir control strategies, drug resistance, poor sanitation, human behaviors, and climate changes. Such changes can lead to the emergence of new CL epidemics. The effective surveillance system should be sustained and extended to all high-risk areas to control the emerging epidemics of ACL and ZCL in the affected areas. Experiences gained during emerging epidemics could be used as a model to develop control programs and also plan future control strategies, particularly in emerging foci, where a gradual or sudden eruption of the new cases of CL occurs.

\section{ACKNOWLEDGMENT}

The authors would like to thank Dr. Hossein Mahmoudvand and Mr. Mohammad Ali Mohammadi for their assistance in preparing the map.

\section{CONFLICT OF INTEREST}

The authors declare that there is no issue related to this article to be conceived as a conflict of interest.

\section{REFERENCES}

1. Postigo JAR. Leishmaniasis in the world health organization eastern mediterranean region. Int J Antimicrob Agents. 2010; 36 : S62-5.

2. World Health Organization. Working to overcome the global impact of neglected tropical diseases: first WHO report on neglected tropical diseases. Geneva: World Health Organization; 2010.

3. Alvar J, Vélez ID, Bern C, Herrero M, Desjeux P, Cano J, et al. Leishmaniasis worldwide and global estimates of its incidence. PLoS One. 2012; 7 (5): e35671.

4. World Health Organization. Report on the interregional meeting on leishmaniasis among neighbouring endemic countries in the Eastern Mediterranean, African and European regions, Amman, Jordan 23-25 September 2018. World Health Organization, Regional Office for the Eastern Mediterranean; 2019. 
5. Desjeux P. Leishmaniasis: current situation and new perspectives. Comp Immunol Microbiol Infect Dis. 2004; 27 (5): 305-18.

6. García AL, Parrado R, Rojas E, Delgado R, Dujardin J-C, Reithinger R. Leishmaniases in Bolivia: comprehensive review and current status. Am J Trop Med Hyg. 2009; 80 (5): 704-11.

7. Bhutto AM, Soomro FR, Baloch JH, Matsumoto J, Uezato H, Hashiguchi Y, et al. Cutaneous leishmaniasis caused by Leishmania (L.) major infection in Sindh province, Pakistan. Acta Trop. 2009; 111 (3): 295-8.

8. Reithinger R, Mohsen M, Leslie T. Risk factors for anthroponotic cutaneous leishmaniasis at the household level in Kabul, Afghanistan. PLoS Negl Trop Dis. 2010; 4(3): e639.

9. Ramaoui K, Guernaoui S, Boumezzough A. Entomological and epidemiological study of a new focus of cutaneous leishmaniasis in Morocco. Parasitol Res. 2008; 103 (4): 859-63.

10. Faiman R, Abbasi I, Jaffe C, Motro Y, Nasereddin A, Schnur LF, et al. A newly emerged cutaneous leishmaniasis focus in northern Israel and two new reservoir hosts of Leishmania major. PLoS Negl Trop Dis. 2013; 7 (2): e2058.

11. World Health Organization. Control of the leishmaniases: report of a meeting of the WHO Expert Commitee on the Control of Leishmaniases, Geneva, 22-26 March 2010. World Health Organization; 2010.

12. Amro A, Gashout A, Al-Dwibe H, Alam MZ, Annajar B, Hamarsheh O, et al. First molecular epidemiological study of cutaneous leishmaniasis in Libya. PLoS Negl Trop Dis. 2012; 6 (6): e1700.

13. Aagaard-Hansen J, Nombela N, Alvar J. Population movement: a key factor in the epidemiology of neglected tropical diseases. Trop Med Int Heal. 2010; 15 (11): 1281-8.

14. Ready PD. Leishmaniasis emergence in Europe. Eurosurveillance. 2010; 15 (10): 19505.

15. Shirzadi MR, Gouya MM. National Guidelines for cutaneous leishmaniasis surveillance in Iran. Minist Heal Med Educ (MOH), Zoonoses Control Dep, Tehran Iran. 2012; 1-78.

16. Daszak P, Cunningham AA, Hyatt AD. Anthropogenic environmental change and the emergence of infectious diseases in wildlife. Acta Trop. 2001;78 (2): 103-16.

17. Askari A, Sharifi I, Aflatoonian MR, Babaei Z, Almani PGN, Mohammadi MA, et al. A newly emerged focus of zoonotic cutaneous leishmaniasis in South-Western Iran. Microb Pathog. 2018; 121: 363-8.

18. Razavinasab SZ, Sharifi I, Aflatoonian MR, Babaei Z, Mohammadi MA, Salarkia E, et al. Expansion of urban cutaneous leishmaniasis into rural areas of southeastern Iran: Clinical, epidemiological and phylogenetic profiles explored using 7SL high resolution melting-PCR analysis. Transbound Emerg Dis. 2019; 66 (1): 1602-10.

19. Bamorovat M, Sharifi I, Aflatoonian MR, Sharifi H, Karamoozian A, Sharifi F, et al. Risk factors for anthroponotic cutaneous leishmaniasis in unresponsive and responsive patients in a major focus, southeast of Iran. PLoS One. 2018; 13 (2): $\mathrm{e} 0192236$.

20. Norouzinezhad F, Ghaffari F, Norouzinejad A, Kaveh F, Gouya MM. Cutaneous leishmaniasis in Iran: results from an epidemiological study in urban and rural provinces. Asian Pac $\mathbf{J}$ Trop Biomed. 2016; 6 (7): 614-9.

21. Ashford RW. The leishmaniases as emerging and reemerging zoonoses. Int J Parasitol. 2000; 30 (12-13): 1269-81.

22. Akhavan AA, Yaghoobi-Ershadi MR, Mehdipour D, Abdoli $\mathrm{H}$, Farzinnia B, Mohebali M, et al. Epidemic outbreak of cutaneous leishmaniasis due to Leishmania major in Ghanavat rural district, Qom Province, Central Iran. Iran J Public Health. 2003; 35-41.

23. Rostami MN, Saghafipour A, Vesali E. A newly emerged cutaneous leishmaniasis focus in central Iran. Int J Infect Dis. 2013; 17 (12): e1198-206.

24. Yaghoobi-Ershadi MR, Hanafi-Bojd AA, Akhavan AA, Zahrai-Ramazani AR, Mohebali M. Epidemiological study in a new focus of cutaneous leishmaniosis due to Leishmania major in Ardestan town, central Iran. Acta Trop. 2001; 79 (2): 115-21.

25. Aflatoonian MR, Sharifi I, Poursmaelian S, Hakimi-Parizi M, Ziaali N. The emergence of anthroponotic cutaneous leishmaniasis following the earthquake in southern villages of Bam district, southeastern Iran, 2010. J Arthropod Borne Dis. 2013; 7 (1): 8-14.

26. Khosravi A, Sharifi I, Dortaj E, Afshar AA, Mostafavi M. The present status of cutaneous leishmaniasis in a recently emerged focus in south-west of Kerman Province, Iran. Iran J Public Health. 2013; 42 (2): 182-7.

27. Sharifi I, Aflatoonian MR, Fekri AR. An epidemic of cutaneous leishmaniasis in Baft district in Kerman Province and its probable causative risk factors. Iran J Epidemiol. 2008; 4 (1): 53-8.

28. Akhavan AA, YaghoubiI Ershadi MR, Hasibi F, Jafari R, Abdoli $\mathrm{H}$, Arandian $\mathrm{MH}$, et al. Emergence of cutaneous leishmaniasis due to Leishmania major in a new focus of southern Iran. Iran J Arthropod Borne Dis. 2007; 1 (1): 1-8.

29. Sharifi I, Nakhaei N, Aflatoonian MR, Parizi MH, Fekri AR, Safizadeh H, et al. Cutaneous leishmaniasis in Bam: A comparative evaluation of pre-and post-earthquake years (19992008). Iran J Public Health. 2011; 40 (2): 49-56.

30. Aflatoonian MR, Sharifi I. The Epidemiology of Cutaneous Leishmaniasis in the City and Suburb of Bam in 2010: Active case-Finding, Treatment and Health Education of the School Children. 2011; 7 (3): 52-57.

31. Sharifi I, Poursmaelian S, Aflatoonian MR, Ardakani RF, Mirzaei M, Fekri AR, et al. Emergence of a new focus of anthroponotic cutaneous leishmaniasis due to Leishmania tropica in rural communities of Bam district after the earthquake, Iran. Trop Med Int Heal. 2011; 16 (4): 510-3.

32. Aghaei Afshar A, Rassi Y, Sharifi I, Vatandoost H, Mollaie HR, Oshaghi MA, et al. First report on natural Leishmania infection of Phlebotomus sergenti due Leishmania tropica by high resolution melting curve method in Southeastern Iran. Asian Pac J Trop Med. 2014; 93-6.

33. Aghaei Afshar A, Rassi Y, Sharifi I, Abai MR, Oshaghi MA, Yaghoobi-Ershadi MR, et al. Susceptibility status of Phlebotomus papatasi and P. sergenti (Diptera: Psychodidae) to DDT and deltamethrin in a focus of cutaneous leishmaniasis after earthquake strike in Bam, Iran. Iran J Arthropod Borne Dis. 2011; 5 (2): 32-41. 
34. Aghasi M, Sharifi I. Survey of the fauna and monthly activity of the sandfly as the vectors of the cutaneous leishmaniasis in the City of Bam. J Kerman Univ Med Sci. 2003; 10 (2): 85-91.

35. Yaghoobi-Ershadi MR, Hanafi-Bojd AA, Javadian E, Jafari R, Zahraei-Ramazani AR, Mohebali M. A new focus of cutaneous leishmaniasis caused by Leishmania tropica. Saudi Med J. 2002; 23 (3): 291-4.

36. Stockdale L, Newton R. A review of preventative methods against human leishmaniasis infection. PLoS Negl Trop Dis. 2013; 7 (6): e2278.

37. Yaghoobi-Ershadi MR, Akhavan AA. Entomological survey of sandflies (Diptera: Psychodidae) in a new focus of zoonotic cutaneous leishmaniosis in Iran. Acta Trop. 1999; 73 (3): 3216.

38. Rassi Y, Saghafipour A, Abai MR, Oshaghi MA, Rafizadeh $\mathrm{S}$, Mehdi M, et al. Phlebotomus papatasi and Meriones libycus as the vector and reservoir host of cutaneous leishmaniasis in Qomrood District, Qom Province, central Iran. Asian Pac J Trop Med. 2011; 4 (2): 97-100.

39. Parvizi P, Ready PD. Nested PCRs and sequencing of nuclear ITS-rDNA fragments detect three Leishmania species of gerbils in sandflies from Iranian foci of zoonotic cutaneous leishmaniasis. Trop Med Int Heal. 2008; 13 (9): 1159-71.

40. Rassi Y, Abai MR, Javadian E, Rafizadeh S, Imamian H, Mohebali M, et al. Entomologie medicale. Bull Soc Pathol Exot. 2008; 101 (5): 425-8.

41. Azizi K, Rassi Y, Moemenbellah-Fard MD. PCR-based detection of Leishmania major kDNA within naturally infected Phlebotomus papatasi in southern Iran. Trans R Soc Trop Med Hyg. 2010; 104 (6): 440-2.

42. Mohebali M, Javadian E, Yaghoobi Ershadi MR, Akhavan AA, Hajjaran H, Abaei MR. Characterization of Leishmania infection in rodents from endemic areas of the Islamic Republic of Iran. EMHJ-Eastern Mediterr Heal J. 2004; 10 (4-5): 591-9.

43. Oshaghi MA, Yaghobi-Ershadi MR, Abbassi M, Parvizi P, Akhavan AA, Foroshani AR, et al. Detection of Leishmania major in naturally infected sand flies using semi nested-PCR. Iran J Public Health. 2008; 59-64.

44. Mirzaei M, Sharifi I, Poursmaelian S. A new focus of anthroponotic cutaneous leishmaniasis and identification of parasite species by nested PCR in Jiroft, Iran. Comp Clin Path. 2012; 21 (5): 1071-5.

45. Fazaeli A, Fouladi B, Sharifi I. Emergence of cutaneous leishmaniasis in a border area at south-east of Iran: an epidemiological survey. J Vector Borne Dis. 2009; 46 (1): 3642.

46. Razmjou S, Hejazy H, Motazedian MH, Baghaei M, Emamy M, Kalantary M. A new focus of zoonotic cutaneous leishmaniasis in Shiraz, Iran. Trans R Soc Trop Med Hyg. 2009; 103 (7): 727-30.

47. Sharifi I, Fekri AR, Aflatoonian MR, Khamesipour A, Mahboudi F, Dowlati Y, et al. Leishmaniasis recidivans among school children in Bam, South-east Iran, 1994-2006. Int J Dermatol. 2010; 49 (5): 557-61.

48. Hejazi H, Mirmohammad SH, Dabirzadeh M, Nilforoushzadeh MA, Baghaei M. Atypical clinical forms of zoonotic cutaneous Leishmaniasis due ro Leishmania major in Isfahan, Iran. 2007; 25 (8): 43-9.
49. Murray HW, Berman JD, Davies CR, Saravia NG. Advances in leishmaniasis. Lancet. 2005; 366 (9496): 1561-77.

50. Ramezany M, Sharifi I, Babaei Z, Ghasemi Nejad Almani P, Heshmatkhah A, Keyhani A, et al. Geographical distribution and molecular characterization for cutaneous leishmaniasis species by sequencing and phylogenetic analyses of kDNA and ITS 1 loci markers in south-eastern Iran. Pathog Glob Health. 2018; 1-10.

51. Bamorovat M, Sharifi I, Mohammadi MA, Eybpoosh S, Nasibi S, Aflatoonian MR, et al. Leishmania tropica isolates from non-healed and healed patients in Iran: A molecular typing and phylogenetic analysis. Microb Pathog. 2018; 116: 124-9.

52. Croft SL, Olliaro P. Leishmaniasis chemotherapychallenges and opportunities. Clin Microbiol Infect. 2011; 17 (10): 1478-83.

53. Khosravi A, Sharifi I, FekriI A, Kermanizadeh A, Bamorovat M, Mostafavi M, et al. Clinical Features of Anthroponotic Cutaneous Leishmaniasis in a Major Focus, Southeastern Iran, 1994-2014. Iran J Parasitol. 2017; 12 (4): 544.

54. Oliaee RT, Sharifi I, Afgar A, Kareshk AT, Asadi A, Heshmatkhah A, et al. Unresponsiveness to meglumine antimoniate in anthroponotic cutaneous leishmaniasis field isolates: analysis of resistance biomarkers by gene expression profiling. Trop Med Int Heal. 2018; 23 (6): 622-33.

55. Aflatoonian MR, Sharifi I, Aflatoonian B, Bamorovat M, Heshmatkhah A, Babaei Z, et al. Associated-risk determinants for anthroponotic cutaneous leishmaniasis treated with meglumine antimoniate: A cohort study in Iran. PLoS Negl Trop Dis. 2019; 13 (6): e0007423.

56. Yaghoobi-Ershadi MR, Jafari R, Hanafi-Bojd AA. A new epidemic focus of zoonotic cutaneous leishmaniasis in central Iran. Ann Saudi Med. 2004; 24 (2): 98-101.

57. Yaghoobi Ershadi MR, Akhavan AA, Zahraei Ramazani A V, Abai MR, Ebrahimi B, Vafaei Nezhad R, et al. Epidemiological study in a new focus of cutaneous leishmaniasis in the Islamic Republic of Iran. East Mediterr Heal J. 2003; 9 (4): 816-26.

58. Pouresmaeelian S, Sharifi I, Aflatoonian MR. A new focus of anthroponotic cutaneous leishmaniasis in Dehbakry region of Bam district, southeastern Iran 2008. J Kerman Univ Med Sci. 2015; 17 (1): 15-24.

59. Fakoorziba MR, Baseri A, Eghbal F, Rezaee S, Azizi K, Moemenbellah-Fard MD. Post-earthquake outbreak of cutaneous leishmaniasis in a rural region of southern Iran. Ann Trop Med Parasitol. 2011; 105 (3): 217-24.

60. Yaghoobi-Ershadi MR, Hakimiparizi M, Zahraei-Ramazani AR, Abdoli H, Akhavan AA, Aghasi M, et al. Sand fly surveillance within an emerging epidemic focus of cutaneous leishmaniasis in southeastern Iran. Iran J Arthropod Borne Dis. 2010; 4 (1): 17-23.

61. Ghaffari D, Parizi MH, Ershadi MRY, Sharifi I, Akhavan AA. A survey of reservoir hosts in two foci of cutaneous leishmaniasis in Kerman province, southeast of Iran. J Parasit Dis. 2014; 38 (3): 245-9.

62. World Health Organization. WHO to implement online epidemiological surveillance for leishmaniasis. 21 June, Geneva, 2016. Available [http://www.who.int/neglected_diseases/ news/WHO_implement_epidemiological_surveillance_leishma niasis/en]. 
63. Hadighi R, Boucher P, Khamesipour A, Meamar AR, Roy G, Ouellette $\mathrm{M}$, et al. Glucantime-resistant Leishmania tropica isolated from Iranian patients with cutaneous leishmaniasis are sensitive to alternative antileishmania drugs. Parasitol Res. 2007; 101 (5): 1319-22.

64. Pour R, Sharifi I, Kazemi B, Zarean M. Identification of nonresponsive isolates to Glucantime in patients with cutaneous Leishmanaisis in Bam. J Kerman Univ Med Sci. 2015; 2 (1): 123-33.

65. Esfandiarpour I, Dabiri SH. Treatment of cutaneous leishmaniasis recidivans with a combination of allopurinol and meglumine antimoniate: a clinical and histologic study. Int $\mathbf{J}$ Dermatol. 2007; 46 (8): 848-52.

66. Nadim A, Motahar M, Houshmand B, Keyghobadi K, Aflatoonian MR. Evaluation of pyrethroid impregnated bednets for control of anthroponotic cutaneous leishmaniasis in Bam (Islamic Republic of Iran). In World Health Organization; 1995; 21.

67. Nadim A, Aflatoonian MR. Anthroponotic cutaneous leishmaniasis in the city of Bam, southeast Iran. Iran J Public Health. 1995; 24 (1-2): 15-24.

68. Noazin S, Shirzadi MR, Kermanizadeh A, Yaghoobi-Ershadi M-R, Sharifi I. Effect of large-scale installation of deltamethrinimpregnated screens and curtains in Bam, a major focus of anthroponotic cutaneous leishmaniasis in Iran. Trans R Soc Trop Med Hyg. 2013; 107 (7): 444-50.

69. Aghaei Afshar A, Vatandoost H, Sharifi I, Rassi Y, Abai MR, Oshaghi MA, et al. First determination of impact and outcome indicators following indoor residual spraying (IRS) with deltamethrin in a new focus of anthroponotic cutaneous leishmaniasis (ACL) in Iran. Asian Pacific J Trop Dis. 2013; 3 (1): 5-9.

70. Saeidi Z, Vatandoost H, Akhavan AA, Yaghoobi-Ershadi MR, Rassi Y, Sheikh Z, et al. Baseline susceptibility of a wild strain of Phlebotomus papatasi (Diptera: Psychodidae) to DDT and pyrethroids in an endemic focus of zoonotic cutaneous leishmaniasis in Iran. Pest Manag Sci. 2012; 68 (5): 669-75.

71. Abolghasemi H, Radfar MH, Khatami M, Nia MS, Amid A, Briggs SM. International medical response to a natural disaster: lessons learned from the Bam earthquake experience. Prehosp Disaster Med. 2006; 21 (3): 141-7.

72. Desjeux P. The increase in risk factors for leishmaniasis worldwide. Trans R Soc Trop Med Hyg. 2001; 95 (3): 239-43.

73. Oshaghi MA, Rasolian M, Shirzadi MR, Mohtarami F, Doosti S. First report on isolation of Leishmania tropica from sandflies of a classical urban cutaneous leishmaniasis focus in southern Iran. Exp Parasitol. 2010; 126 (4): 445-50.

74. Yaghoobi-Ershadi MR, Akhavan AA, Mohebali M. Monthly variation of Leishmania major MON-26 infection rates in Phlebotomus papatasi (Diptra: Psychodidae) from rodent burrows in Badrood area of Iran. Med J Islam Repub Iran. 2001; 15 (3): 175-8.

75. Abai MR, Oshaghi MA, Tajedin L, Rassi Y, Akhavan AA. Geographical distribution and ecological features of the great gerbil subspecies in the main zoonotic cutaneous leishmaniasis foci in Iran. Asian Pac J Trop Med. 2010; 3 (10): 800-3.

76. Ershadi M-RY, Zahraei-Ramazani A-R, Akhavan A-A, Jalali-Zand A-R, Abdoli H, Nadim A. Rodent control operations against zoonotic cutaneous leishmaniasis in rural Iran. Ann Saudi Med. 2005; 25 (4): 309-12.

77. Yaghoobi-Ershadi MR, Akhavan AA, Zahraei-Ramazani AR, Javadian E, Motavalli-Emami M. Field trial for the control of zoonotic cutaneous leishmaniosis in Badrood, Iran. Ann Saudi Med. 2000; 20 (5-6): 386-9.

78. Yaghoobi-Ershadi MR, Akhavan AA, Mohebali M. Meriones Iibycus and Rhombomys opimus (Rodentia: Gerbillidae) are the main reservoir hosts in a new focus of zoonotic cutaneous leishmaniasis in Iran. Trans R Soc Trop Med Hyg. 1996; 90 (5): 503-4.

79. Bamorovat M, Sharifi I, Mohammadi MA, Harandi MF, Mohebali M, Afshar RM, et al. Canine visceral leishmaniasis in Kerman, southeast of Iran: a seroepidemiological, histopathological and molecular study. Iran J Parasitol. 2014; 9 (3): 342.

80. Bamorovat M, Sharifi I, Dabiri S, Mohammadi MA, Harandi MF, Mohebali M, et al. Leishmania tropica in stray dogs in southeast Iran. Iran J Public Health. 2015; 44 (10): 1359-66.

81. Abbaszadeh MJA, Sharifi I, Bamorovat M, Mohebali M, Bahreini MS, Naderi A. Canine Visceral Leishmaniasis; A Seroepidemiological Survey in Jiroft District, Southern Kerman Province, Southeastern Iran in 2015. Iran J Parasitol. 2018; 13 (1): 67-71.

82. Moshfe A, Mohebali M, Edrissian G, Zarei Z, Akhoundi B, Kazemi B, et al. Canine visceral leishmaniasis: asymptomatic infected dogs as a source of $L$. infantum infection. Acta Trop. 2009; 112 (2): 101-5.

83. Mohebali M, Hajjaran H, Hamzavi Y, Mobedi I, Arshi S, Zarei Z, et al. Epidemiological aspects of canine visceral leishmaniosis in the Islamic Republic of Iran. Vet Parasitol. 2005; 129 (3-4): 243-51.

84. Sharifi I, Fekri AR, Aflatonian M-R, Khamesipour A, Nadim A, Mousavi M-RA, et al. Randomised vaccine trial of single dose of killed Leishmania major plus BCG against anthroponotic cutaneous leishmaniasis in Bam, Iran. Lancet. 1998; 351 (9115): 1540-3.

85. Noazin S, Modabber F, Khamesipour A, Smith PG, Moulton LH, Nasseri K, et al. First generation leishmaniasis vaccines: a review of field efficacy trials. Vaccine. 2008; 26 (52): 6759-67.

86. Sharifi F, Sharifi I, Zarean M, Parizi MH, Aflatoonian MR, Harandi MF, et al. Spatial distribution and molecular identification of Leishmania species from endemic foci of southeastern Iran. Iran J Parasitol. 2012; 7 (1): 45-52.

87. Aflatoonian MR, Sharifi I, Parizi MH, Fekri AR, Aflatoonian $\mathrm{B}$, Sharifi M, et al. A prospective cohort study of cutaneous leishmaniasis risk and opium addiction in south eastern Iran. PLoS One. 2014; 9 (2): e89043.

88. Tangie LN, Desmond A, Aminde LN, Ako AM, Halle PM. Cutaneous leishmaniasis in a severely immunocompromised HIV patient in Kumbo, Northwest region of Cameroon: case report. BMC Res Notes. 2017; 10 (1): 425.

89. Bamorovat M, Sharifi I, Fekri A, Keyhani A, Aflatoonian MR, Heshmatkhah A, et al. A single-group trial of end-stage patients with anthroponotic cutaneous leishmaniasis: Levamisole in combination with Glucantime in field and laboratory models. Microb Pathog. 2019; 128: 162-70. 
90. Gupta S. Return of kala-azar. J Indian Med assossiation. 1991; 65: 89-90.

Cite this article:

Aflatoonian MR, Sharifi I, Babaei Z, Sharifi F, Keyhani A, Salarkia E, Khosravi A, Khamesipour A, Mohebali M, Nadim A, Bamorovat. Emerging Epidemics of Cutaneous Leishmaniasis in Iran: Operational Aspects, Management and Implemented Control Approaches. J Med Microbiol Infect Dis, 2019; 7 (3): 52-60. DOI: 10.29252/JoMMID.7.3.52 